\title{
Hombres que trabajan y beben - chicas que fuman: roles de género en la bohemia osornina a mediados del siglo XX
}

Doménica Francke

\begin{abstract}
Resumen
En Chile, la prostitución como fenómeno social e histórico se encuentra escasamente estudiado y, generalmente, se lo representa como una actividad femenina, invisibilizando en su análisis el rol de los varones-clientes en su desarrollo. En este artículo se resalta la condición relacional de los roles de género manifestados en el seno de la bohemia de la ciudad de Osorno, en torno a su cuarto centenario, el año 1958, sobre todo en lo que respecta a la prostitución. Además, se vincula el desarrollo de las actividades bohemias con el contexto económico de la época, revelando sus ambivalentes pero fuertes relaciones.
\end{abstract}

Palabras clave: prostitución - bohemia - modernidad - género.

\begin{abstract}
In Chile, prostitution as a social and historical phenomenon has been poorly studied and it is generally represented as a female activity, making invisible in the analysis the role of maleclients in their development. In this article, it is emphased the relational status of gender roles as expressed in the heart of the bohemia of Osorno city, around its fourth centenary, in 1958, especially in regard to prostitution. In addition, it links the development of bohemian activities with the economic context of those times, revealing his ambivalence but strong relationships.
\end{abstract}

Key words: prostitution - bohemia - modernity - gender.

Este artículo se deriva de la investigación desarrollada en el marco de la tesis de grado Hombres que trabajan y beben - chicas que fuman: Modernidad, bohemia y roles de género en la sociedad osornina (1950-1958). Profesora de Historia y Geografía, Licenciada en Educación, Universidad de los Lagos, Osorno, Chile. 


\section{OSORNO IV CENTENARIO}

La década de 1950 constituirá uno de los mejores momentos de la economía agroganadera de la ciudad de Osorno. Además de las cifras de este auge, resulta fundamental que ha quedado establecida, por el imaginario local, como una etapa esplendorosa y pujante. De acuerdo con Carreño (2008), este auge agro-ganadero puede ser apreciado siguiendo el itinerario de la Sociedad Agrícola Ganadera de Osorno (SAGO), máximo ente gremial de los empresarios locales: para 1945, controlaba 38 criaderos de bovinos, 7 de ovinos, 2 de porcinos y 5 de equinos, de alta calidad.

Una fuente de antecedentes en este sentido es la historiografía local, representada por Peralta y Hipp (2004), Grothe (2003) y, más recientemente, Oyarzo (2007). Otra fuente de gran valor resulta ser el diario local La Prensa, específicamente para el año '58, año del cuarto centenario de Osorno. En las páginas de este último comprobaremos la multiplicación de celebraciones a medida que se acercaba el cuarto centenario de la ciudad.

Surgirán, consolidados, una estructura productiva y un mercado laboral de tipo moderno, disciplinario y salarial, así como espacios y tiempos de evasión y/o esparcimiento entre los trabajadores. A estos espacios y tiempos los denominaremos genéricamente la bohemia osornina, en la cual ubicaremos prácticas como el comercio sexual establecido y el consumo inmoderado de alcohol. Respecto al origen del término, asociado a la vida alegre y marginal, citaremos la literatura francesa de mediados del siglo XIX y la imagen de la vida del artista alejado de los preceptos morales burgueses. Henry Murger (1855) en Escenas de la vida bohemia propagará esta imagen. En palabras de Álvarez (2003), se trata de un movimiento que se concentró en cuestionar los ideales morales burgueses, anteponiendo una vida alegre, de excesos y amores fáciles a la reconcentrada disciplina de la productividad y el esfuerzo personal.

La relación entre mercado laboral moderno y bohemia la estableceremos en dos sentidos: i l la necesaria existencia de una capacidad de consumo por parte de los trabajadores (disponibilidad de dinero para gastar en servicios y productos no estrictamente vitales); y ii) el uso del tiempo libre, alejado del trabajo y sus implicancias disciplinarias, nos pondrá en contacto con espacios de evasión y reafirmación identitaria.

Respecto a la economía osornina, abundan las impresiones positivas del desempeño del campo, destacando su modernidad y grado de eficiencia productiva, asociado a la mecanización de los procesos:

"Tan ágil y dominante fue esa preocupación, que pronto los campos de Osorno, Purranque, Río Negro, San Pablo y otros pueblos se infestaron con su mecánica presencia. Sonreían los jefes de las firmas importadoras, tales como Dunkan, Fox, Wessel, Dubal y Cía. y Williamson Balfour y Cía. vendiendo maquinarias al contado violento sin peticiones de rebajas (...) principió Osorno a causar la admiración de Chile"(Ojeda, 1956: 14; Aguilera, 1958: 36). 
Considerando la elevada inversión que requiere la adquisición de las maquinarias descritas y la disponibilidad de liquidez, podríamos decir que las arcas de los empresarios agro-ganaderos de Osorno gozan de buena salud. Por otro lado, la racionalidad económica, aplicable a los aludidos de acuerdo a su perfil de negocios, nos hace pensar que las expectativas de buenos resultados son altas y las posibilidades de conflictos o inestabilidades que amenacen la inversión, bajas.

Lo más destacado por los observadores es el origen del auge: las actividades agroganaderas. Destacaremos que los elogios se centran en el carácter moderno de la actividad y en la aplicación de tecnologías.

En base a los datos entregados, constatamos, en primer lugar, el fenómeno de buen tránsito económico y visible dinamismo de la ciudad. En segundo lugar, la raíz de la prosperidad está situada en las actividades agro-ganaderas, que hacen patente su carácter moderno.

Así, la ciudad se acerca a cumplir 400 años y para su celebración no se escatiman recursos materiales ni discursivos. Esto es apreciable en constantes titulares del periódico La Prensa del año 1958, donde muchas de sus páginas anunciarán inauguraciones, desfiles conmemorativos y referencias al IV centenario, tal como la editorial correspondiente al sábado 4 de enero del mismo año:

"(...) En su mensaje a la ciudadanía, el Jefe Comunal saludó el año 1958 como la iniciación de esta fecha histórica trascendental para nuestra ciudad y solicitó (...) la debida e indispensable cooperación. (...) Estamos en el deber ineludible de ofrecérsela (...) porque es necesario e imprescindible que la impresión que selleven de la ciudad quienes nos visiten corresponda exactamente al grado de superación y la madurez cívica que Osorno sustenta" (La Prensa, 1958).

Probablemente, otra explicación de la buena impresión de los viajeros acerca del progreso osornino sea el hecho de que un sector importante e influyente de la población lo siente así y está empeñada en demostrarlo. Una prueba de ello es una carta redactada el 19 de enero de 1958 por el "Comité IV Centenario", dirigida al diario local, donde se manifestaba que "este Comité, en su sesión de la presente semana, tomó conocimiento (...) de la eficaz cooperación del Diario 'LA PRENSA' (. . ) a la finalidad de destacar el significado de tan extraordinario acontecimiento histórico (....)" (Ibíd: 4).

A la celebración del cuarto centenario asiste el Presidente de la República, Carlos Ibáñez del Campo, quien acude al Te Deum celebrado por el Primer Obispo de Osorno, Francisco Valdés (Grothe, Op. cit.). En fotografías de la época, se aprecia un cortejo de damas notables llegando a la catedral, encabezadas por la esposa del Presidente, 
Graciela Letelier. De fondo, las fuerzas militares garantizan que todo se desarrolle con el debido orden ${ }^{3}$.

El ánimo de fiesta es innegable y, en medio del jolgorio, nos atrevemos a preguntar si esta convocatoria del progreso alcanza a toda la sociedad y si están ausentes los conflictos y los márgenes oscuros.

En estos márgenes de la modernidad es precisamente donde rastrearemos a los asalariados, pernoctando en prostíbulos y bares. También encontraremos prostitutas y otras mujeres de baja extracción social: lavanderas, dueñas de casa, etc., sorprendidas en la calle o involucradas en delitos menores. Pero debemos considerar que esto no significa que los asalariados sean víctimas impotentes de los procesos económicos, y aquí señalamos especialmente a los hombres. Ciertamente, estos procesos los incluyen de manera subordinada frente al capital, pero observamos que su incorporación al consumo de servicios no necesariamente vitales, posiblemente considerados evasivos o de lujo, constituye un factor de cohesión social y les otorga, si no la realidad, al menos la ilusión de libertad en el uso de ciertos tiempos y espacios. Esto, de acuerdo a Castel (1997), es posible sólo mediante la adquisición de poder comprador con la venta de su fuerza de trabajo.

En este sentido, coincidiremos con Foucault (1992 y 1998) respecto a la capacidad creadora del poder, vale decir, que una interpretación del poder moderno como violento y destructor cae en torpes simplismos sentimentalistas. El poder no sólo prohíbe; también genera placer y seduce, no se mantiene estático ni puede ser considerado como un objeto que pertenece a unos/as y del que otros/as son despojados/as, pues el poder circula en la sociedad. Se plantea, entonces, un poder positivo, omnipresente y generador de subjetividades tanto productivas como familiares, sexuales, etcétera.

Por último, nos moveremos sobre la pregunta acerca de si estos poderes actúan por igual en hombres y mujeres, y si es posible encontrar manifestaciones de desigualdad insertas en estructuras más profundas, como el sistema sexo-género patriarcal, incluso en la bohemia. Y por qué no, sobre todo en la bohemia, ya que resulta un espacio especialmente cargado de tensiones por su carácter evasivo respecto al trabajo, esa carga particularmente masculina (Servicio Nacional de Estadística y Censos, 1952).

\section{LA BOHEMIA: ESPACIO DE EVASIÓN-SOCIALIZACIÓN MODERNO}

Nos gustaría constatar dinámicas sociales imbricadas en la luminosa esfera ordenproductividad, que resultan, a la vez, alternativa y consecuencia de las estructuras productivas y sociales modernas. 
Bohemia es el nombre que tentativamente daremos al fenómeno que integra en su seno consumo de prostitución y de alcohol por parte de un sector de hombres osorninos. Usaremos el término bohemia con la condición de que conservemos sus implicancias de marginalidad, entendida como"(.. .) vida que se aparta de las normas y convenciones sociales (...)" (RAE, 2001); pero aún contenida, establecida y permitida en el interior del luminoso mundo de la producción y el orden moderno.

Tanto Castel (1997) como Offe (1992) han planteado que una sociedad salarial es aquella en la cual el trabajo es considerado fuente de toda riqueza y en la que se establece esta actividad como central en la vida de las personas, constituyéndose en el principal canal de ingresos y elementos identitarios. Asimismo, esta sociedad salarial plantea ciertas exigencias sobre los individuos. En este sentido, diremos que la bohemia nace sólo cuando ha quedado suficientemente establecida la separación moderna de los tiempos de trabajo y ocio, así como los espacios en que se desarrolla cada actividad, por ser básicamente incompatibles.

Ahora, siguiendo a Castel (Op. cit.) y Thompson (1995), este nacimiento está condicionado por las nuevas relaciones de poder modernas. En otras palabras, y de acuerdo con Foucault (1998), resulta también un espacio permeado por el poder en su dimensión creadora y condicionante.

Al menos entre los años 1950 y 1960, apreciaremos en distintas fuentes la existencia de una sociabilidad bohemia frecuentada por hombres de sectores trabajadores, un buen número de origen rural, y también por empresarios y comerciantes (Programa de Estudios y Documentación en Ciencias Humanas [PEDCH], 2007). Espacialmente, se puede situar al interior de la ciudad de Osorno, vale decir, en el sector de Rahue, la población Angulo y la calle Prat (plano 1). Como veremos más adelante, se presenta una actividad estratificada según ingresos de los clientes, precios y calidad del servicio.

Cabe destacar la distribución de estas actividades: Ios sectores identificados en 1950 eran periféricos, de reciente poblamiento o reconocidos como poblaciones obreras. Este alejamiento del centro comercial-histórico es propio de las ciudades modernas que desarrollan lógicas de segregación socio-espacial. Nos referimos específicamente a una separación de la población de acuerdo a sus niveles de ingresos.

Planteamos estas ubicaciones de acuerdo a tres fuentes: en primer lugar, ediciones del diario osornino La Prensa de los años 1921, 1941-1942, 1949, 1950-1960, donde aparecen como sitios en que ocurren constantemente hechos delictuales relacionados mayormente al consumo de alcohol y, en menor medida, al comercio sexual. En segundo lugar, los Archivos Judiciales del Segundo Juzgado del Crimen de Osorno, correspondientes a la Primera Comisaría de Osorno y proporcionados por el Programa de Estudios y Documentación en Ciencias Humanas de la Universidad de Los Lagos. Estos archivos corresponden a los partes enviados por la Primera Comisaría de Rahue y la Prefectura de Osorno entre los años 1950 y 1951, en los que se denuncia, sobre 
todo, la circulación en la vía pública en estado de ebriedad. Por último, los testimonios orales de personas de la época -recabados por Leonardo Oyarzo (2007)- que frecuentaban estos lugares o estaban de alguna manera relacionadas con los sectores y/o la actividad bohemia o conocían de su existencia, como se constatará más adelante.

No señalaremos los espacios bohemios osorninos en su totalidad, sólo lo realizamos para los fines de este trabajo y en base a las fuentes mencionadas. Dejaremos abierta la posibilidad de la existencia de centros bohemios que no aparezcan en este estudio y que podrían ser detectados ampliando fuentes y criterios.

Respecto a la periodización establecida, cabe señalar que ya desde 1920 es posible advertir en el diario La Prensa la presencia de denuncias de excesos derivados del consumo de alcohol y el clandestinaje al interior de la población Angulo. Incluso, el mismo medio dio a conocer un miércoles 9 de agosto de 1941 la muerte de dos carabineros en un local de dicha población identificado como prostíbulo, noticia que produjo gran revuelo. Sin embargo, este trabajo se centrará en un momento que hemos identificado como de auge, entre 1950 y el cuarto centenario en 1958, periodo delimitado de acuerdo a su relación más explícita con la economía local. Se trata de un momento de mayor intensidad, causado por las dinámicas económicas y presente con fuerza en las fuentes revisadas.

\section{Clientes populares: bohemia y ejercicio de masculinidad}

De las fuentes señaladas, se puede extraer que la mayor parte de los hombres implicados en la bohemia, ya sea de origen rural o urbano, ejercen actividades relacionadas con el campo, las cuales no necesitan mayor preparación formal. Además, entre ellos, predominan los gañanes y jornaleros. Tenemos un escenario, entonces, en el que para ser cliente de estos lugares se debe contar con ingresos y, en este caso, esos ingresos están relacionados con el trabajo agrícola (Servicio Nacional de Estadística y Censos, Op. cit.).

Sin embargo, como veremos más adelante, existen notorias excepciones que, precisamente por esta condición, no se mezclan geográficamente con el grupo de los trabajadores que pasaremos a analizar a continuación.

Se presenta un amplio dominio masculino en los trabajos agro-ganaderos. Así, no resulta extraño encontrarnos con que la mayor parte de los identificados en los archivos judiciales sean hombres. Vivar (2007) nos revela que de un total de 2.225 detenciones, 2.179 están protagonizadas por hombres (un 98\%) y sólo 46 por mujeres.

Los datos tabulados de los archivos judiciales de los años 1950 y 1951 arrojan los siguientes resultados en cuanto a las ocupaciones de los detenidos por ebriedad: 


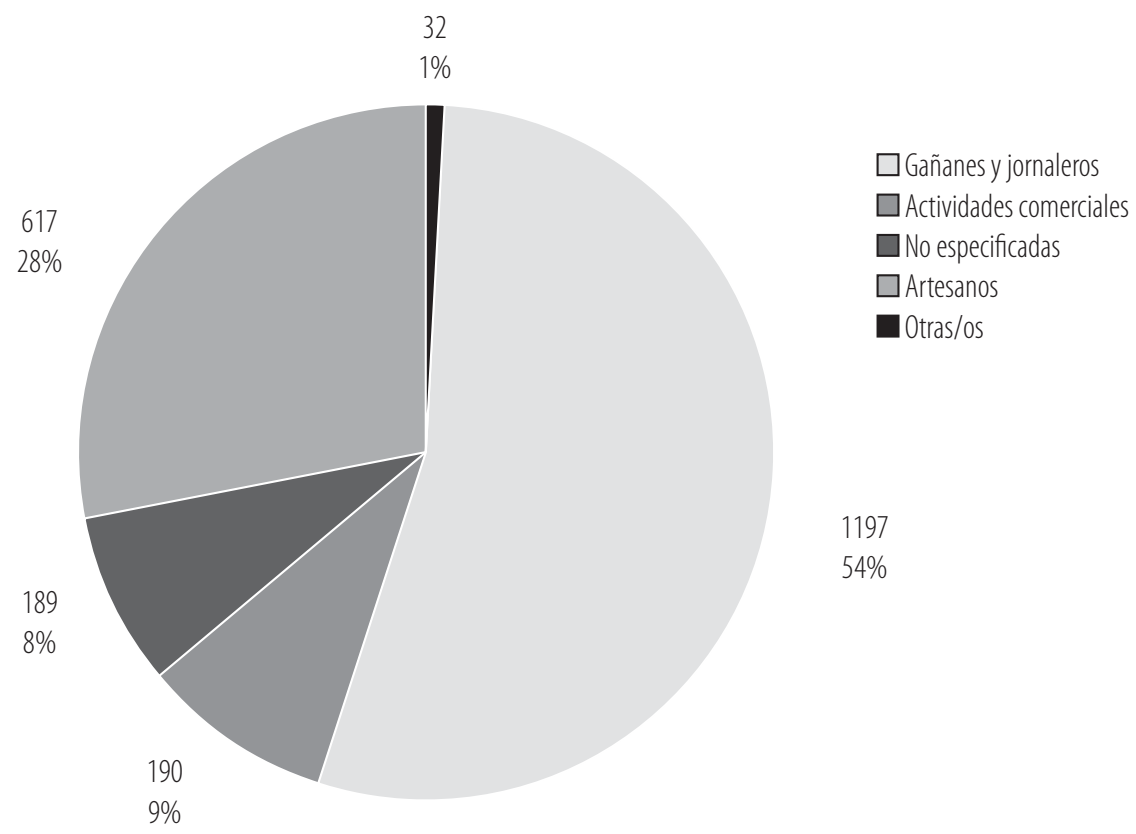

Fuente: elaboración propia en base a Vivar (2007).

Los gañanes y jornaleros sobresalen con un 54\% del total de detenciones. La revisión directa de los archivos judiciales, para un período más corto, lo corrobora4. Señalaremos que los datos entregados por Vivar (Ibíd.) sólo especifican el sexo en los casos de quienes se pudo identificar como mujeres ejerciendo la prostitución, y hemos podido constatar tanto su participación en las detenciones como el involucramiento de dueñas de casa, lavanderas, comerciantes y empleadas domésticas, entre otras.

Con respecto a la gran cantidad de trabajadores de origen rural detenidos, una explicación posible dice relación con su condición específicamente rural, ya que luego del término de las actividades bohemias éstos quedarían deambulando por las calles o caminarían para salir de regreso a sus lugares de origen, mientras los clientes urbanos se desplazaban mucho más rápida y fácilmente a sus hogares. Por otro lado, estas cifras se refieren a detenciones y no así a detenidos, pues, como veremos para el caso específico de las mujeres, los nombres de las/os protagonistas pueden repetirse.

Además, diversos testimonios dan cuenta del fenómeno de prevalencia de actividades agro-ganaderas entre los aludidos, por ejemplo, Francisco Avendaño cuenta que: "(...) de Osorno me acuerdo que llegaba a trabajar en las temporadas de verano, para el trigo (... .)" (Ibíd: 39). Por su parte, Juan Leviñanco menciona que "los fines de semana eran cosa seria, yo y otros paisanos, veníamos del campo a puro tomar, nos íbamos a los bares 
de la población Angulo (...) a veces tocaba que no tenía trabajo y me quedaba, incluso varios días (... .)" (Ibíd: 77). Por último, Alex Sunquel comenta que "como trabajadores la gente del campo era buena, y muy responsable también, pero a la hora que se largaban a tomar lo hacían casi tan bien como su trabajo (...)" (Ibíd: 85).

Otro factor importante para nuestra matriz analítica radica en que la asistencia a los lupanares o casas de prostitución está directamente relacionada con el tiempo de ocio de los clientes, pues dedicaban fines de semana completos a gastar el dinero de arduas jornadas de trabajo (perfilado como el principal mecanismo de adquisición de capacidades de consumo, resultando éstas una válvula de escape de su propia disciplina). Según el testimonio producto de una entrevista realizada por la autora el 8 de agosto de 2009, al matrimonio de Humberto y Rosa, los trabajadores rurales bajaban a la ciudad con el dinero de un mes o más de trabajo y realizaban sus compras en las tiendas de la ciudad. Luego, acudían a los sitios bohemios gastando profusamente en alcohol y/o prostitutas.

La preponderancia del papel masculino en la bohemia se confirma con la existencia de esposas sumisas y comprensivas, las cuales aceptaban como prerrogativa masculina el acceso a la bohemia. Ésta se origina precisamente a través de la ocupación de otro espacio masculino: el trabajo productivo. Margarita se refiere en los siguientes términos a la conducta de su marido: "(. . ) se iba los días domingos y a veces no volvía hasta dos o tres días después, se iba a Prat, yo no me enojaba, porque él trabajaba tanto, así que estaba bien que se relajara" (Ibíd: 58).

En esta línea, sobre el rol asignado a las mujeres, Brunilda manifiesta que en su caso "mis padres me dijeron cuando cumplí 18 años, que ya era hora de empezar a buscar marido, y que tenía que ser bueno y trabajador, y yo serle responsable atendiéndolo y criando a mis hijos" (Ibíd: 72). El papel de trabajador se asocia a la masculinidad popular en el imaginario y valores de esta mujer y sus padres, quienes, al mismo tiempo, le "enseñan" su propio rol en esta relación: sumisión y maternidad responsable frente al varón verdadero (que trabaja). Se realiza una división sexual del trabajo, la que no está exenta de relaciones de poder y subordinación, como plantea Pateman (1995).

Según los testimonios de Margarita y Brunilda, ambas coinciden al situar el trabajo como factor fundante de las masculinidades de sus maridos y, en el caso del esposo de la primera, en su certificado de derecho para relajarse en los días de descanso.

En palabras de los clientes, el trabajo y la bohemia estaban relacionados entre sí, como complementarios: "era común que el que no tomase fuese tratado como maricón (...) si no tomabas no podías salir a ninguna parte (...) Mi propio padre, que en paz descanse, me decía: 'tenís que tomar no más, hombre; tenís que hacerte hombre' (...) La primera 


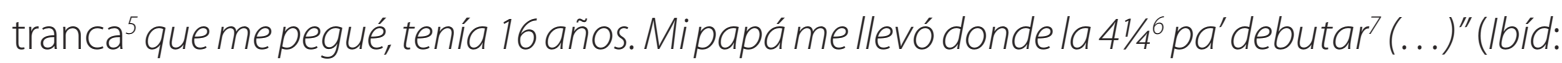
77). El "cliente" que otorga este testimonio, René Sobarzo, identifica claramente lugares y prácticas del proceso de hacerse hombre: por un lado, la bohemia ayuda a formar y confirmar la masculinidad y, por otro, el alcohol y acceso a las mujeres son parte del dominio masculino por excelencia, esto es, quien no es un hombre verdadero (un maricón) no posee las capacidades para acceder a la bohemia.

Por su parte, el diario La Prensa y los empresarios de la época en múltiples ocasiones dieron a conocer sus temores de que el consumo de alcohol de los trabajadores afectara la producción. Lo anterior constituye una forma de reconocer el problema, pero también de indicar la necesidad de que éste se mantuviera dentro de los márgenes de lo aceptable, es decir, que no afectara la estructura productiva de la zona. Hay una recurrencia al discurso moralista, esta vez, al basado en la moderna racionalidad económica reinante (Naredo, 2003: 188). Al respecto, La Prensa publicó el domingo 30 de julio de 1950 un artículo titulado "La ebriedad como factor negativo en la producción". Posteriormente, y con el mismo espíritu, apareció el 12 de mayo de 1955 otro titulado "Agricultura y ausentismo".

El mismo cliente entrevistado reafirma la importancia de beber con estas palabras: "(...) de repente, cuando nos juntábamos a tomar, hacíamos competencias de quién era mejor p'al chupe ${ }^{\prime \prime}$ (Vivar, Op. cit: 79). Vemos que la masculinidad se demuestra frente a los otros hombres y no sólo frente a las mujeres, situación que nos recuerda la condición de espacio de homosociabilidad tanto del trabajo como de la bohemia. Se trata de una condición relacional y dinámica, como plantean Fachel (1998), Rubin (1986) y Scott (2003) y, si seguimos esta lectura, incluso es posible perder esta condición, dejando de practicarla, lo que equivale a convertirse en maricón: máximo crimen y negación de la masculinidad.

\section{Estratificación socioeconómica y masculinidad en la bohemia}

Con respecto a cierta segmentación socioeconómica presente en la bohemia osornina, generalmente se señala a la población Angulo (donde se ubican las calles Amunátegui y Lastarria) y al sector de Rahue como lugares de encuentro del bajo pueblo. Mientras, calle Prat es resaltada como exclusiva y de mayor nivel, vetando a quienes poseían una humilde fuente de ingresos y, consecuentemente, eran consumidores más limitados. En este sentido, revisemos un testimonio:"(...) donde vivían los pijecitos

Borrachera (las cursivas son nuestras).

Todo indica que se refiere a un prostíbulo, sin embargo, debido a que no aparece señalado en otros testimonios o por fuentes de otro tipo, lo relacionamos con el popular Amunátegui 444, como veremos, frecuentemente mencionado por la prensa y los partes policiales.

Debutar alude a tener la primera relación sexual.

Chupe significa beber alcohol (las cursivas son nuestras). 
era re-bonito, si hasta la calle Prat era pa' los de plata, nosotros si queríamos ir donde las chicas que fuman teníamos que ir a Angulo o a Amunátegui" (Vivar, Op. cit: 41).

Sobre esta característica de la bohemia abundan los testimonios y consideraremos como establecido el carácter selectivo y exclusivo de las casas de prostitución de la calle Prat. Al respecto, el trabajo de Leonardo Oyarzo (2007) arroja valiosos antecedentes, sobre todo testimonios de vecinos del sector como Erwin Brikisak, quien señala:

"A la Nelly y la Zelinda no entraba cualquier compadre porque eran casas caras, un obrero por ejemplo, no podía entrar, ahí entraban empleados con buenos puestos, patrones de fundo y comerciantes (...) Con la plata que ocupaban en la Nelly y la Zelinda podían disfrutar dos veces en otro prostíbulo, porque todas las cosas en estos prostíbulos eran buenas, desde las piezas hasta las camas" (Oyarzo, 2007: 124).

La Nelly y la Zelinda son afamadas y ricas regentas de prostíbulos de calle Prat, que se tomaban el lujo de seleccionar clientela entre los más pudientes. Sobarzo, cliente antes citado, reconoce, en su condición de asalariado de labores agrícolas, que "(...) los que tenían plata se iban pa' Prat, yo en cambio tenía que ir a Angulo (... . 10" (Vivar, Op. cit: 58).

Otros vecinos de Prat, como Irma Caiguán y Raúl Vargas, coinciden con esta versión y agregan importantes antecedentes:

"Estaba el Mom Matre, la Zelinda, la Carmen, la Nelly, Ana Polanco, la Rucia Barrientos, su nombre era Fermina Barrientos, los prostíbulos estaban ubicados entre Praty Amtahuer.

En ese tiempo esas mujeres que usted veía, no creía que eran del ambiente, eran muy bonitas, las mayores tenían entre 20 y 26 años. Cada prostíbulo tenía entre 10 a 20 mujeres (...) La Zelinda era dueña del edificio Trumao, eran tremendas casas, (...) bien decentes, eran bien pintadas, la de la Zelinda era celeste, la de la Nelly era azulito, la de la Polanco era amarilla, tenían un color característico. Uno cuando entraba, encontraba sillones de cuero que se hundian, espejos grandes (...)

Los que iban ahi eran pura gringuería, turquería, en Prat casi todos los prostíbulos eran de clase alta (...)" (Oyarzo, Op. cit: 125-126).

La denominación gringo hace referencia al color claro del pelo de los clientes, asociado en la zona a la colonización alemana y, consiguientemente, a la condición de patrones de fundos aledaños, comerciantes o empresarios, es decir, a una alta capacidad de consumo. Asimismo, los dueños de fundo también son mencionados como clientes por el Sr. Brikisak:

$9 \quad$ Esta denominación para las prostitutas aparece en varios testimonios rescatados por el ya citado estudio de Vivar (las cursivas son nuestras).

10 En el testimonio se continúa manifestando que la "4 1/4" quedaba en Angulo, por lo que nuestras sospechas de que el prostíbulo mencionado en realidad sea Amunátegui 444 se fortalecen. 
"(...) de pronto llegaban del campo huasos con plata, estaban dispuestos a pagar lo que sea. Un gallo que tenía fundo estaba con mi papá en un prostíbulo y él cuenta que estaban ahi y le decía a la cabrona que apague la hueá de radio, y la mujer le decía que no y éste sacó un revólver y le pegó un balazo y cagó la radio. Después le dijo '¿cuánto cuesta tu hueá?'y se la pagó" (Ibíd: 123).

Por su parte, turco es la denominación que reciben popularmente los inmigrantes árabe-sirios, quienes se instalan en el siglo XX en la ciudad y se dedican principalmente al comercio (Julián, 2003). Evidentemente, sobre todo en el caso de los gringos, estos clientes no se mezclaban con los trabajadores con quienes probablemente mantenían relaciones laborales.

A los locales ya mencionados para calle Prat, debemos agregar los siguientes: Nanking Club, Lirio Azul, Pusicat y El Edén, El Bombillou, El Mogambo, La Uca y el de María Trompa, que habría sido ilegal. Entre todos los testimonios recogidos por Oyarzo (Ibíd.), es posible contabilizar 14 prostíbulos. Ahora, muchas veces no se menciona el nombre del local sino el nombre o apodo de la dueña, como es el caso de María Báez, quien se reconoce nuera de Zenaida Martínez, la regenta del María Trompa.

Esto parece confirmar, en primer lugar, el esplendor de la actividad, situado por los/ as entrevistados/as entre 1950 y 1970. Alrededor de esta última década habría decaído por efecto del toque de queda impuesto por la dictadura militar, como han dado a conocer los estudios hechos por Olavarría (2001) y Valdés y Olavarría (1998). En segundo lugar, se puede comprobar la convergencia en señalar el grado de estratificación de la bohemia, que separaba a los dos polos de la relación productiva capital-trabajo, pero permitía a ambos participar de ella desde sus capacidades de consumo diferenciadas, como se evidencia en la investigación de Oyarzo (Op. cit.).

Para fortalecer estas versiones, citaremos a Zenaida Escobar, quien señala:

"El barrio en esos años, a pesar de que todos hablaban de la calle Prat, la calle de las prostitutas, en el día no se veían prostitutas, como a las 8 comenzaban a aparecer, y si salían iban a los controles en el poli11 Carrera a hacerse sus exámenes, pero el barrio era tranquilo (...) Ninguna mujer era insolente, eran mujeres que vivían su vida y sabían respetar (...) Los médicos, los bomberos que eran conocidos de mi madre también iban a los prostíbulos. También capitanes de carabineros, llegaba casi siempre gente decente ${ }^{12 "}$ (Ibíd: 127-128).

\footnotetext{
Policlínico.

12 Cabe mencionar que en otro extracto de este testimonio se menciona el Elefante Blanco, elegante y exclusivo prostíbulo de la época; sin embargo, esto no se repite en los otros testimonios. La falta de antecedentes hace que no lo abordemos en este estudio, unido al hecho de que está ubicado fuera de nuestro circuito bohemio definido.
} 
Llama la atención la importancia que se da al carácter reservado y observante del orden del comercio sexual del sector, contraponiéndolo a las características de lugares asociados a clientes asalariados. Respecto al rompimiento de esta tranquilidad en ciertos sectores y circunstancias dentro de la bohemia, lo abordaremos más adelante en el apartado dedicado al componente femenino del ambiente. Por ahora diremos solamente que, de acuerdo a los archivos judiciales, tres mujeres identificadas como prostitutas en los partes son detenidas en la calle Prat: Eliana Inostroza Ruiz, María Rebolledo Rebolledo y Olga Navarrete Navarrete.

Ya hemos hablado de la condición dinámica y relacional de la masculinidad de los clientes; es así como en el apartado anterior nos concentramos en los asalariados, que ocupan su tiempo de ocio y el dinero ganado mediante el trabajo en estas actividades. Ahora, frente al escenario desafiante que nos plantea calle Prat, con sus exclusiones y exclusividades, cabe preguntarnos qué lleva a estos hombres pudientes y adinerados a acudir a los prostíbulos. Intentaremos responder desde la lectura ofrecida por Pateman (1995), en El contrato sexual.

Tenemos, entonces, una bohemia de clase media-alta, ubicada, claramente por los testimonios, en la calle Prat. El Sr. Brikisak hace reiteradamente referencia al nivel de los locales de esta calle: "(...) había un caserón grande que se desarmó, (. . .) en las noches de invierno, cuando habían grados bajo cero, tú llegabas y entrabas; estaba calientito y las comadres al lado. jAh! y no dejaban entrar a cualquiera, tú tocabas el timbre y de adentro te miraban, entonces si te veían medio rasca no te dejaban entrar" (Oyarzo, Op. cit: 122-124).

Igualmente, los mismos testimonios señalan a los sectores de Angulo y Rahue como parte de un circuito más bien humilde y de corte popular, frecuentado preferentemente por trabajadores, los que, además, desempeñan en su mayoría labores del campo e incluso provienen de sectores rurales. Estos sujetos son constantemente detenidos por circular en estado de ebriedad en la vía pública y/o se ven involucrados en otros ilícitos, como riñas o desórdenes, razones por las que protagonizan muchos partes policiales, de acuerdo a los archivos judiciales revisados por la autora.

Al reparar en este aspecto de la bohemia, y en especial de la prostitución, quisiéramos hablar sobre la existencia de un contrato sexual que actúa como garante y base del contrato social, el cual establece al menos una condición de igualdad para los hombres, y no para la humanidad. Se trata de una fraternidad masculina que asegura, al menos, un derecho, de modo que suaviza sus diferencias en otros planos, como el económico, sobre el que nos hemos concentrado. Este derecho es el acceso garantizado a las mujeres.

Si bien están separados tanto por la geografía de la bohemia osornina como por sus niveles de ingresos, hay una característica que une a estos hombres, más allá de cualquier diferencia o tensión (recordemos la condición de empleadores y de asalariados de unos y otros), y es la necesidad de acceder sexualmente a las mujeres. Si 
asumimos -como asume el sistema sexo/género patriarcal-que los hombres poseen - o son poseídos por- una sexualidad insaciable, las prostitutas y la prostitución son necesarias para ambos grupos. En Prat también se menciona el silencio de las esposas, como afirma Orlando Soto: "(.. .) las mujeres no decían nada porque estaban acostumbradas" (Ibíd: 129). Es una callada aceptación de este fenómeno por parte de mujeres que no lo frecuentan, frente al masculino poder de satisfacer masculinas necesidades. En los testimonios femeninos frecuentemente se destaca la reserva de las prostitutas de Prat como una gran virtud. Una "mujer de familia", entonces, exige el recato, no la eliminación del comercio sexual, tal como se desprende de los testimonios que ya revisamos de Zenaida Escobar, además de la Sra. Caiguán y del Sr. Vargas.

Manteniendo un orden jerárquico socioeconómico desigual, injusto en muchos sentidos y foco de conflictos a veces, estos hombres establecen una alianza que los iguala frente y con respecto a las mujeres. Pobres o ricos, cansados de sus roles productivos, se distraen y mantienen su masculinidad resguardada con alcohol y mujeres. Así, la bohemia se constituye, junto al trabajo, en uno de los espacios de homosociabilidad.

\section{Las chicas que fumaban y el conflictivo rol femenino en la bohemia}

De acuerdo a lo planteado por Góngora (1994) sobre el problema de la carencia de fuentes para los estudios históricos de la prostitución, podemos decir que la participación femenina en los circuitos bohemios es más difícil de rastrear, pues los únicos documentos oficiales que se refieren a éstos (archivos judiciales) están ampliamente protagonizados por hombres. Ya mencionamos a las mujeres que se mantienen en el hogar como guardianas de la familia y fieles esposas. Veamos ahora hasta qué punto y bajo qué formas las otras mujeres participan en la bohemia.

Los archivos judiciales señalan sobre todo, pero no sólo, a los ebrios, y podemos extraer de sus páginas información concerniente al número, las edades, el nivel de escolaridad, las ocupaciones y el sexo de los/as infractores/as. Las mujeres representan una minoría en estas detenciones, pero esto mismo nos da una idea bastante exacta respecto a la división sexual de los espacios de la bohemia. Entre otros aspectos, la mayoría de quienes resultan detenidas ejercen la prostitución. En este sentido, es interesante analizar cuáles son las causales específicas de las detenciones, pues se verá que la prostitución no cabe en esta categoría ya que se encuentra tácitamente aceptada y normalizada. Respecto a esto último, se debe tener en cuenta que "la prostitución fue reglamentada en 1896, con fines higiénico-policiales; autorizándose de este modo su ejercicio a toda mujer que voluntariamente quisiese practicarla y se inscribiese en los registros municipales especialmente abiertos para tales efectos: la Oficina de Casas de Tolerancia" (Góngora, 1994: 39). 
De un total de 2.225 detenciones entre 1950 y $1952^{13}$, sólo 46 están protagonizadas por mujeres (un 2\%) e incluso algunas se repiten como infractoras. De ellas, la implacable mano policial nos permite detectar el caso de Laura Miranda, quien, coincidentemente, señala como dirección particular Amunátegui 444, misma ubicación de un conocido prostíbulo de la ciudad, de carácter popular. Además, en 1950 aparece en dos ocasiones Eulogia Gómez, analfabeta y dueña de casa de 48 años, señalada por carabineros como infractora constante ${ }^{14}$ (PEDCH, Op. cit.). Incluyendo a Laura Miranda, 16 mujeres son calificadas abiertamente como prostitutas, quedando señalado en los partes cursados. Además, siempre resultan detenidas en compañía de hombres ebrios.

Entre las no identificadas como prostitutas, Isabel Quintana Cárdenas, casada, dueña de casa de 20 años de edad, es detenida el 30 de abril de 1950 al interior del mencionado Amunátegui 444 junto a Julio Jara y Efraín Cárdenas. Este hecho nos despierta cierta sospecha sobre sus actividades, al menos en el momento de la detención. El respectivo parte señala que "estas tres personas fueron detenidas a las 23:30 horas, en el interior del prostíbulo clandestino ubicado en la calle Amunátegui No 444, por el Vice 10 Carlos Arras Coloma y Carabinero Orlando Ojeda"15" (Ibíd: s/p).

Respecto al carácter transgresor de las prostitutas y su alejamiento de la noción de mujer-madre-esposa de la familia nuclear moderna (Pateman, Op. cit.), Ilama poderosamente la atención la denominación que los testimonios masculinos recogidos por Vivar (Op. cit: 41 y 58) le dan: las chicas que fuman, lo que podría interpretarse como una forma de constatar en el lenguaje la condición marginal de estas mujeres, su alteridad frente a la normalidad femenina hogareña. Asumiremos, entonces, que una mujer "de familia" no fumaba o era mal visto que lo hiciera. 


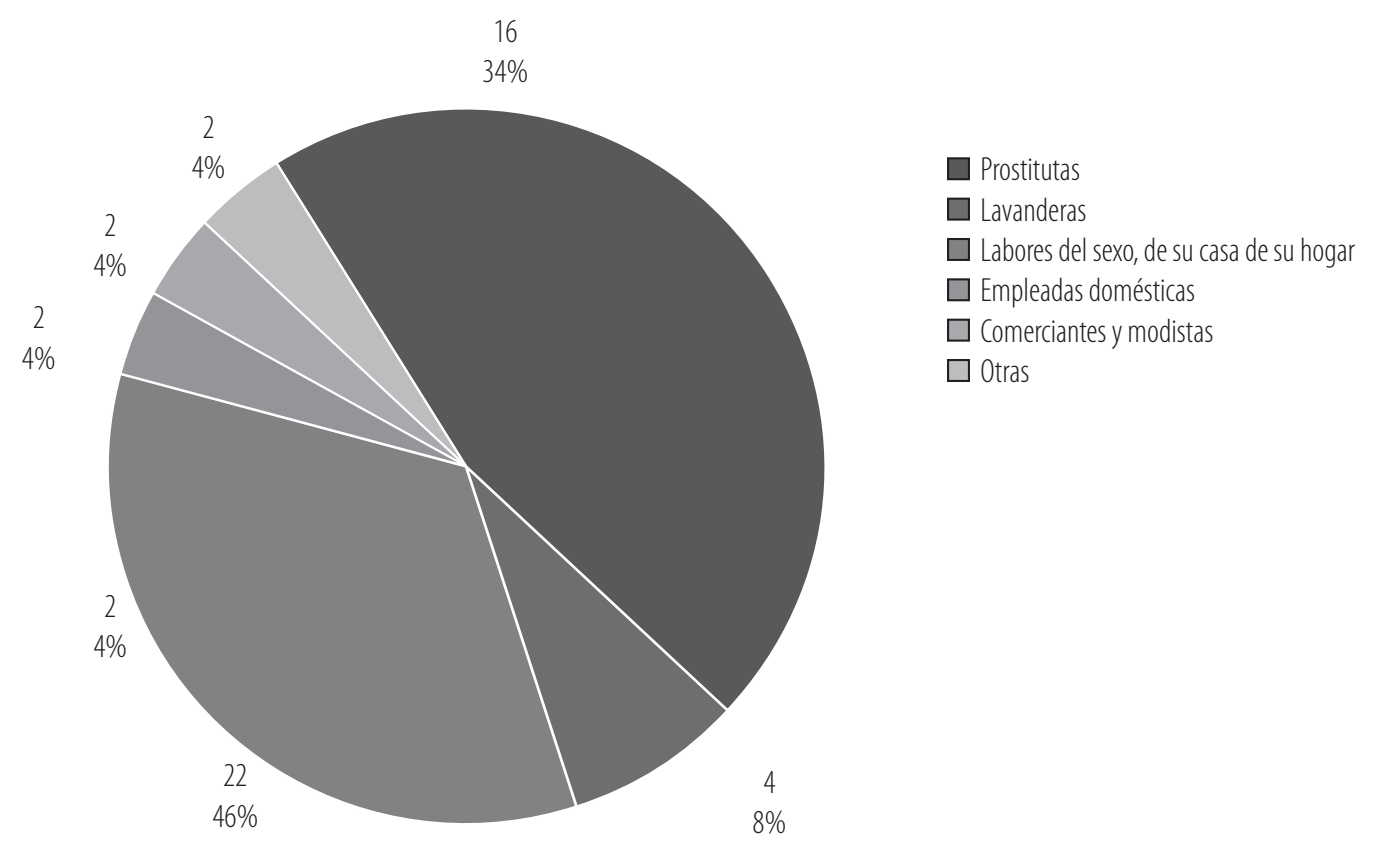

Fuente: elaboración propia en base a PEDCH (2007).

En el gráfico № 2 vemos el número de detenciones de mujeres, no de detenidas, pues, como ya se ha señalado, hay nombres que se repiten en los registros. Es notorio el hecho de que estas mujeres se desempeñan mayoritariamente en las denominadas labores del sexo y sus afines (labores de casa/del hogar) lo que nos muestra una clara tendencia tradicionalista en lo que se refiere a ocupaciones femeninas. Sin embargo, ellas se ponen al margen de la ley y participan en hechos delictivos, manifestando aspectos conflictivos de sus roles de género tradicionales.

Además, la enorme cantidad de prostitutas involucradas en estos incidentes nos hace pensar que, por excelencia, una forma de participación de las mujeres en la vida bohemia es la prostitución. Por último, las mujeres trabajadoras que siguen en número a las prostitutas protagonizando incidentes son lavanderas y empleadas domésticas. Considerando el pequeño universo de la muestra, no deja de ser interesante que las ocupaciones que desempeñan coincidan con áreas de servicio tradicionalmente femeninas y en esto confirmarían las tendencias mostradas por el Censo de 1952 en cuanto a ocupaciones urbanas de Osorno en 1950: una sexuación productiva.

Los gráficos siguientes consideran el número de detenidas, esto es, un total de 46, y a partir de su análisis es posible establecer más detalles sobre éstas. 


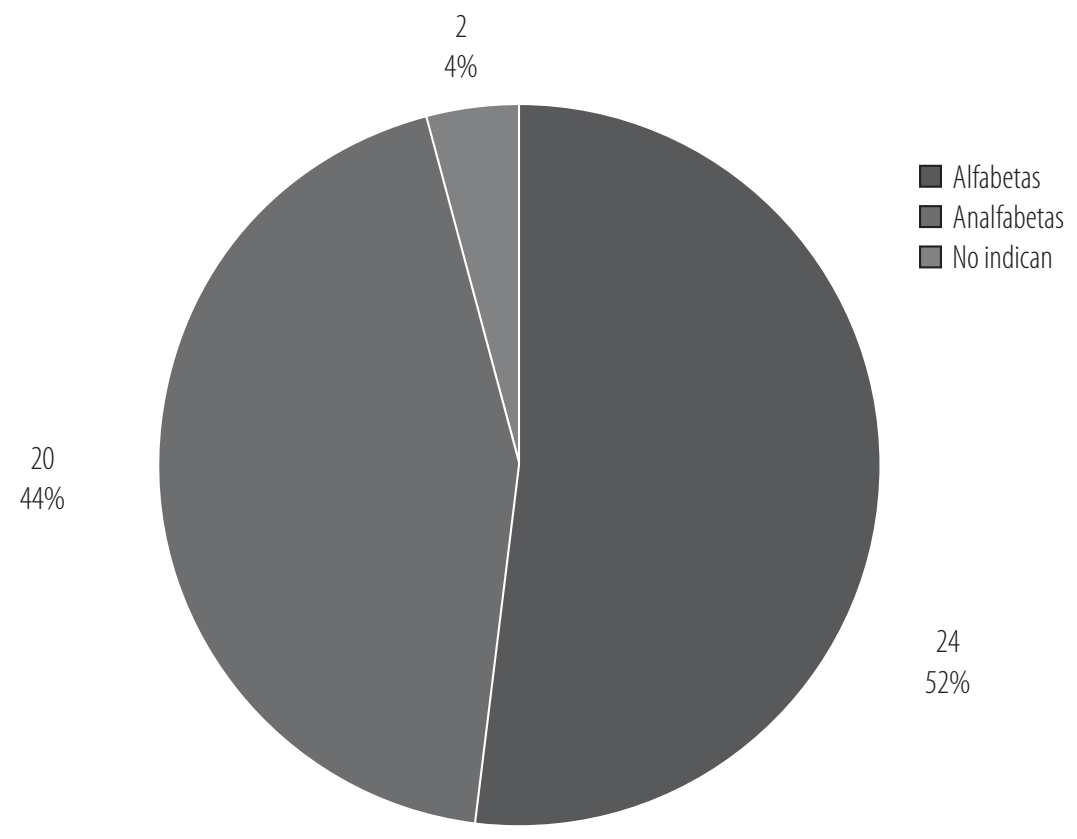

Fuente: elaboración propia en base a PEDCH (2007).

Es notable el altísimo nivel de analfabetismo presente entre las detenidas (gráfico 3). En un principio, se puede hacer una lectura respecto a su condición socioeconómica para explicarlo. Sin desmentir lo anterior y complementándolo, diremos que aquí se aprecia una fuerte discriminación por género. Esta tendencia se repite si analizamos las cifras arrojadas por el Censo de 1952, en el cual, para el área urbana, de un total de 7.063 analfabetos/as, un 33\% son hombres, mientras en el caso de las mujeres la cifra se eleva hasta un 67\% (Servicio Nacional de Estadística y Censos, Op. cit.). Entonces, no podríamos circunscribir esta condición a la esfera de las personas involucradas en estas actividades marginales, sino que deberíamos entenderla como manifestación de un fenómeno más amplio que afecta a la población osornina femenina en general.

Vivar (Op. cit.) realizó este cálculo para un período más extenso sobre la base de los mismos archivos y el mismo grupo humano involucrado en las detenciones por ebriedad, para los hombres, encontrando que el $86 \%$ de los detenidos contaba con algún nivel de alfabetización, desagregándose de la siguiente forma: un 27\% lee y escribe; un 47\% tiene educación primaria; sólo un 5\% Humanidades y un 7\% no indica. El 14\% era analfabeto $y$, si bien se trata de una cifra alta en general, es muy baja si se la compara con las mujeres encontradas en prácticamente los mismos registros. 


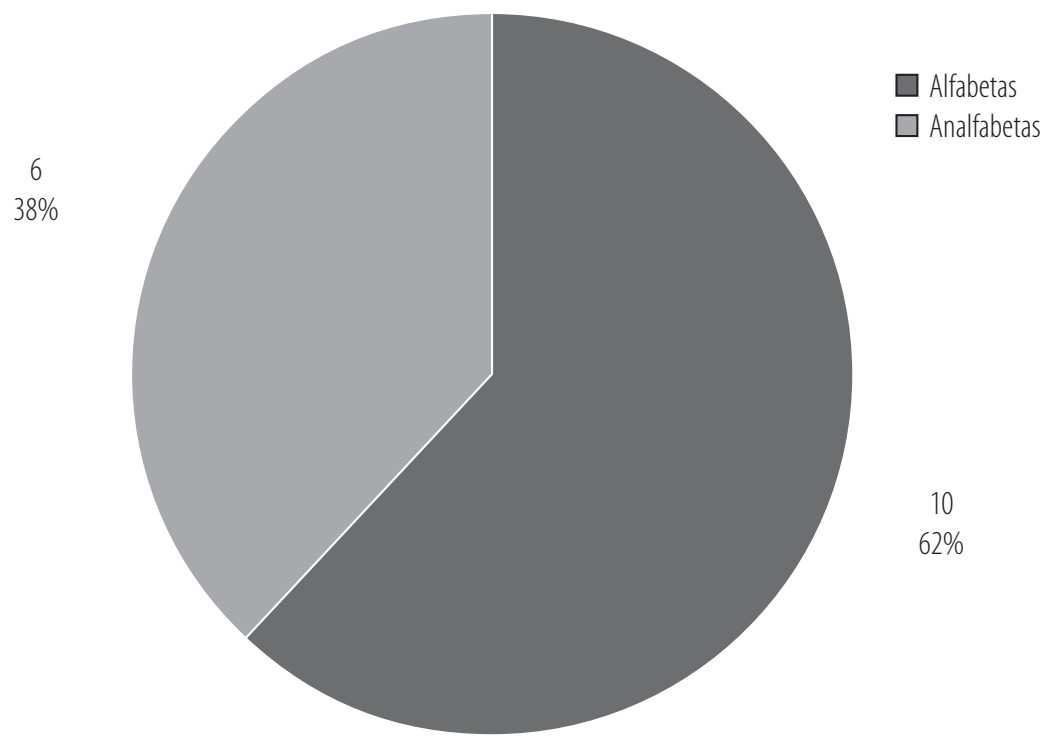

Fuente: elaboración propia en base a PEDCH (2007).

Ahora, llama la atención que en el sub-grupo de las prostitutas (gráfico 4) los niveles de analfabetismo desciendan, aunque levemente, ubicándose en un 38\%. Por su parte, el nivel de alfabetismo aumenta un 10\%, con un total de $64 \%$ de prostitutas que al menos saben leer y escribir.

Otro punto a destacar dice relación con los lugares en que se realizan las detenciones de las prostitutas, pues podemos establecer ciertas coincidencias con los espacios señalados como de ejercicio de la prostitución. Es así como se menciona en los partes policiales: i) la calle Amunátegui, específicamente el número 444; ii) la calle Prat, conocida por sus casas de prostitución de alto nivel; iii) el sector de Lastarria, que los vecinos de Prat (la Sra. Caiguán y el Sr. Vargas) mencionan en su testimonio; iv) la presencia de "El Colgante" cuya propietaria sería presumiblemente Silvia Lemus; y v) por último, se identifica el sector de Rahue como lugar recurrente de detenciones. Estas ubicaciones coincidirían con el mapa de los prostíbulos osorninos de la época presentado en la tesis de pregrado de Cristina Vásquez (2009).

"El Colgante", señalado como prostíbulo de baja estofa, protagoniza la siguiente noticia el 18 de noviembre de 1953:

"Pendencia en prostíbulo clandestino:

Anoche, cerca de las 24 horas, fueron detenidas cinco mujeres y ocho individuos por Carabineros, a causa de haberse producido una pendencia en el prostíbulo clandestino Ilamado "El Colgante", ubicado en calle Lastarria esquina Errázuriz, después de haber estado bebiendo en ese lugar. A consecuencia de esta pendencia 
resultó un herido, pero que no fue encontrado por haberse dado a la fuga. Entre los detenidos se encuentra un famoso cuatrero de apellido Poza, que era buscado por la justicia. Los otros detenidos son obreros camineros que se encontraban fuertemente armados, algunos, de revólver" (La Prensa, 1953: 5).

Aquí cabe recordar los discursos moralistas que asociaban a los cuatreros que asolaban los campos osorninos a una vida bohemia bajo la forma del consumo de alcohol. El cuatrerismo sería la forma de hacerse de dinero para estas diversiones (La Prensa, 1922, 1929; Agricultura Austral, 1936). Además, los clientes señalados aparecen constantemente en contacto con estas mujeres, preferentemente relacionados con actos delictuosos. Basta recordar el suceso aparecido en las páginas del diario La Prensa el miércoles 9 de agosto de 1941, donde en la población Angulo mueren dos carabineros al interior de un prostíbulo.

En la misma línea, otro de estos hechos es señalado por el periódico el 15 de abril de 1949, bajo el titular "Ayer fue capturado autor de homicidio perpetrado en casa de tolerancia":

"Ayer en la mañana fue capturado en la población Rahue, Luis Alberto Gutiérrez Gutiérrez, (a) 'El Gitano,', quien en la noche del miércoles último de una puñalada dio muerte a Rosario Reyes Ovando. Escenario del hecho de sangre fue el prostíbulo de Amunátegui 444, de frecuente mención en la crónica roja osornina" (La Prensa, 1949: 6).

Este delincuente, al ser detenido, manifiesta tristeza y arrepentimiento sobre lo ocurrido, pues la "Chayo", la prostituta asesinada, no habría sido el blanco inicial de su ataque, sino una víctima del azar al interponerse entre el autor y la persona a quien éste habría atacado por no darle su vuelto luego de pagar su consumo de alcohol. Para "El Gitano", este crimen sería deshonroso y, en sus palabras, "lo peor" que haya hecho en su vida. Sobre todo, nos parece rescatable la relación más bien amistosa que parece haber establecido este hombre con la mujer asesinada. Si bien las prostitutas cumplían un rol de corte tradicional en el sistema sexo-género patriarcal, vale decir, estar al servicio de los hombres, incluso sexualmente, poseían una extraña cualidad dual, habitando codo a codo con ellos espacios prohibidos a las esposas tradicionales. Este fenómeno es corroborado por los testimonios que revisamos de las esposas de estos hombres de la bohemia, como los casos de Margarita y Brunelia (Vivar, Op. cit: 58, 72).

Ahora, las mujeres prostitutas cumplían su rol en las sociedades patriarcales en los márgenes del orden social, pero como algo necesario para conservar el mismo. Agregaremos que la aceptación silenciosa de la existencia de burdeles se veía sancionada por la realización de rondas médicas, escoltadas por carabineros, las cuales fiscalizaban que las prostitutas estuvieran al día con respecto a sus controles de enfermedades venéreas. Por ejemplo, "el médico salía en compañía de carabineros a los restoranes, y aquella chiquilla que veía más de dos días seguidos era llevada (...) detenida. Y se le advertía que tenía que hacerse un tratamiento contra las enfermedades venéreas, si no, la 
seguirían llevando presa" (Ibíd: 72). Como vemos, se trata de una actividad silenciada, pero oficialmente valorada, al punto que se aplica sobre ella una política sanitaria.

Sin embargo, estas prácticas dejan al descubierto otra dimensión de las relaciones de género en la bohemia, esta vez enfocadas en la prostitución en particular, a saber: la violencia y el tratamiento de estas mujeres como objetos. Sus cuerpos son revisados, fiscalizados y certificados para que puedan dar un buen servicio, sin afectar a los clientes, quienes no son sometidos a esta vigilancia sanitaria. Nos parece un ejemplo flagrante de la consideración de la mujer, al menos en su encarnación prostituta: no hay intercambio sin objeto. Al respecto, Fraisse (2008) realiza un interesante análisis del fenómeno de transformación del cuerpo en objeto, es decir, de su separación del "yo" y la posibilidad que esta idea abre de la venta del cuerpo como parte de la propiedad privada de los individuos.

Con respecto a la vigilancia sanitaria, los testimonios son claros. Zenaida Escobar cuenta que "si salían [las mujeres prostitutas] iban a los controles en el poli Carrera a hacer sus exámenes" (Oyarzo, Op. cit: 127). De la misma forma, María Angélica Báez menciona que "tenían un doctor que las veía todas las semanas, (. . .) tenían un carné de sanidad, con lo cual podían acceder a trabajar, si no, no podían" (Ibíd: 132).

Nuevamente, sólo la consideración moderna del cuerpo como objeto hace posible la prestación de servicios sexuales con garantías y legislaciones incluidas. A modo de ejemplo, ya en 1918 se publicó en el Diario Oficial de la República de Chile la Ley No 3.384, una proto-legislación sanitaria que consideraba la regulación del comercio sexual. Pero, además, se establece un discurso en torno a los lugares apropiados para el ejercicio de este comercio, es así como el espacio privado, al interior del prostíbulo, la reserva y el silencio son altamente valorados. Tomemos como ejemplo las tres detenciones ocurridas en calle Prat que revisamos anteriormente, en contraste con la repetida opinión respecto a la tranquilidad y buenos modales de las prostitutas del sector.

Una forma de explicarnos estos hechos es la mención que se hace en los testimonios de la existencia de prostitutas de población, que cobraban menos y asistían a Prat para ofrecer sus servicios en plena calle, rompiendo así el acuerdo tácito entre los/as vecinos/as y los prostíbulos. Estas mujeres están presentes en, al menos, tres testimonios de vecinas/os de Prat (los Sres. Caiguán y Vargas, el Sr. Soto y la Sra. Báez, tomados de Oyarzo [Op. cit: 126, 129, 132]) y, por otro lado, en entrevista realizada por la autora del presente artículo, Rosa compara su tranquila vida como empleada doméstica inserta en el espacio privado con la de estas mujeres de la calle y la noche.

\section{Bohemia/sociedad: una relación contradictoria}

No sólo el rompimiento del carácter necesariamente privado de la bohemia, circunscrita en los márgenes urbanos, implicó la reacción de la autoridad. Recordemos la condición básica de las detenciones descritas: el desorden público, vale decir, la ocupa- 
ción de la calle para realizar actividades que molestaban al vecindario. Las prostitutas detenidas, así como todas/os las/os sancionadas/os, lo fueron por estar en la calle, no por ejercer o consumir prostitución. Esto nos indica la aceptación del fenómeno, aunque con ciertas reservas: las del recato e invisibilidad.

En este sentido, según la distribución espacial de la bohemia osornina (plano 1), incluso cuando la actividad está reservada para clientes con altos ingresos (como en el caso de Prat, lo mismo que para los asalariados que frecuentan Angulo o Rahue) se trata aún de sectores periféricos. En el plano de la ciudad de Osorno de 1960 se puede apreciar cómo los espacios de la bohemia están convenientemente apartados del corazón civilizado de la ciudad. Los testimonios así lo confirman: Prat es descrita como una calle que en la época de auge de la prostitución termina en arboledas en las que se puede practicar la caza y, además, se ubica la cárcel, otra institución moderna aceptada como necesaria, pero comúnmente separada de los centros civilizados de la urbe. Angulo y Rahue, por su parte, son paradigmáticos en tanto espacios de manifestación de la ciudad bárbara, escenarios poblados por personas acusadas de constantes faltas a la urbanidad, focos de inmoralidad y conflicto (Ibíd: 123, 125). Esto es confirmado en los archivos judiciales y en los periódicos de la época revisados por la autora. Sobre todo en el caso de Angulo, las denuncias sobre su condición de foco de problemas alejado de la mano de la autoridad aparecen desde 1921.

En esta población, de origen reciente y raíz socio-económica trabajadora, en 1952 se denuncia una vez más la presencia de "elementos extraños" en estado de ebriedad que perturban el orden. Llama la atención el hecho de que La Prensa se adjudique la representación de las inquietudes del vecindario hablando en su nombre, por ejemplo, en la ya mencionada noticia del asesinato de dos carabineros ocurrido en agosto de 1941. También se involucra a los/as vecinos/as en los reclamos por la presencia de bares y prostíbulos en la población, quienes piden la instalación de un retén precisamente en el lugar en que se ubicó un lupanar, es decir, se reemplaza el antro por un evidente símbolo y materialización del orden.

Asimismo, en su edición del 26 de junio de 1952, el periódico denunciaba el consumo desmedido de alcohol y su relación con los prostíbulos. Posteriormente, el 14 de marzo de 1955, relacionaba directamente en sus páginas alcohol y prostitución como males que favorecen la barbarie, escribiendo: "Característico y poco edificante espectáculo ofrece especialmente en las noches de los sábados, la población Angulo de nuestra ciudad. Al amparo de las sombras y escaza (sic) vigilancia policial surge el clandestinaje alcohólico a través de los prostíbulos incontrolados" (La Prensa, 1955: 6).

Hay un aspecto repetitivo en las denuncias de La Prensa, y es que no sólo pide la erradicación del alcoholismo, también destaca el carácter clandestino de los expendios de alcohol (que asocia a la prostitución y al delito). Es notoria la imbricación entre operar dentro de la legalidad, pagando impuestos, y pasar desapercibido a los ojos denunciantes de este medio. En el caso de los locales de calle Prat, la única vez que se 
les menciona es el 27 de julio de 1954, donde se dice precisamente que sobre ellos se aplicará una estricta vigilancia del cumplimiento de las normativas legales.

Contrariamente, Amunátegui 444 ocupa innumerables páginas del diario bajo la acusación de operar clandestinamente. Lo mismo sucede, aunque en menor medida, con "El Colgante". A modo de ejemplo, podemos citar las ediciones de La Prensa del 13 de abril de 1921; 15 de abril de 1949; 16 de agosto de 1953; 18 de noviembre de 1953; 26 de junio de 1952 y lunes 14 de marzo de 1955. Situación similar ocurre en partes policiales, en los que se señala también la clandestinidad del local. De hecho, asumimos que esta sería la razón para que incluso se realicen detenciones en su interior.

A partir de ello, podemos deducir que una de las formas de legitimación que estos lugares poseen es el pago de impuestos, inevitablemente traducido en un aporte a las arcas fiscales y al buen tránsito económico de la ciudad. De testimonios de vecinos/as de calle Prat, podemos extraer el modus operandi de las chicas que fuman y cuál era su relación con las regentas y el Estado:

\begin{abstract}
"las prostitutas tenían la obligación de estar hasta las 5 de la mañana (...) tenían cada una su pieza y no tenían un sueldo fijo, la cabrona cobraba la pieza antes de irte a acostar y lo que la prostituta le hacía gastar al cliente en tragos (...) La dueña ganaba por arriendo de pieza y por trago. Un trago podía costar 500 escudos (...)" (Oyarzo, Op. cit: 123-124, 132).
\end{abstract}

En contraste, las callejeras, también llamadas patines, "no cobraban mucho, esas mujeres eran perseguidas por Carabineros porque no portaban su carné de identidad (...) habian peleas con las patinadoras, porque andaban en la calle" (Ibíd: 126, 132). Desde nuestro punto de vista, no sólo el aspecto sanitario confabulaba para que las callejeras fueran perseguidas por la ley, sino también el hecho de que constituían una competencia desleal -barata y evasora de impuestos- para los prostíbulos establecidos. En concordancia con esto último, las clandestinas (callejeras), según la versión de las elites, hacían su inmundo comercio en plena vía pública (Góngora, 1994: 128 y ss.).

De hecho, las páginas de La Prensa anuncian el aumento del impuesto a los locales de expendio de alcohol, precisamente con ocasión del IV centenario. La noticia se hacía pública un viernes 28 de septiembre de la siguiente manera: "(. . ) los impuestos que sean cancelados dentro de la comuna de Osorno (...) se pagarán recargados con un cinco por ciento sobre su monto (...)" (La Prensa, 1958: 7). De esta forma, los lupanares, bares, etc., que podían representar focos de problemas para la autoridad también constituyen un aporte a sus arcas y, específicamente, a la fastuosidad de las celebraciones.

A la par, se desarrolla una campaña anti-alcohol fuertemente publicitada, al igual que el supuesto alcoholismo de grandes masas trabajadoras. Para el año 1959, las páginas de La Prensa informan tanto de la decisión del Municipio de aumentar las patentes de alcoholes como de la gran cantidad de vecinos/as que se interesan en el negocio, 
solicitándolas "para instalar negocios de venta de bebidas alcohólicas" (La Prensa, 1959: 6). Hay una relación ambigua, fluctuante y hasta contradictoria entre autoridades y medios que denuncian el consumo de alcohol como una lacra y la prostitución como oscuro escenario de crímenes y excesos, pues no por ello pueden negar su importancia en la economía de la ciudad, ni el interés en estos "vicios" de respetables autoridades y vecinos, quienes, a su vez, jamás serían señalados como parte de la causa de los desórdenes que se denuncian.

Así, los mismos discursos oficiales que no dudaron en condenar y asignar culpas por el exceso de consumo de alcohol y por el desagradable ambiente de los burdeles prefirieron dejar en la sombra la búsqueda de las causas y alcances de las mismas actividades. En este escenario, la vida urbana, su economía y legalidad parecen disociadas de las actividades nocturnas bohemias y, en la mayor parte de los casos, estas últimas sólo acaparan la atención y son claramente señaladas cuando se ven envueltas en incidentes desagradables y/o ilegales.

El consumo de alcohol, e incluso el comercio sexual, pueden considerarse elementos de la economía urbana de Osorno que cargan sobre sus hombros parte de la luminosidad de la moderna "ciudad de riquezas y paraíso del turismo" (La Prensa, 1958: 5). Un paraíso complejo, diremos, y lleno de contrastes, que quizás viva su éxito a pesar de y también lo deba a la existencia misma de dichos contrastes.

\section{CONCLUSIONES}

El asalariado -con sus capacidades adquiridas mediante el trabajo-y el espacio de ocio de la bohemia resultan efectos de la modernidad y de su dinámica tanto económica como social. Lejos de estar desligados o de ser contradictorios, los circuitos del trabajo y de la bohemia no son posibles ni se entienden el uno sin la otra y viceversa. Incluso, el lado visible de la modernidad osornina cobra literal tributo al comercio bohemio de cuerpos y alcohol (recordemos el cobro extra de impuestos al alcohol para celebrar el IV centenario).

En su etapa de mayor esplendor, Osorno refugia en sus calles y noches a personajes sobre los que generalmente se guarda silencio y sólo adquieren visibilidad en su etapa productiva y racional. A veces, también, surgen como quebrantadores de la ley y de las buenas costumbres, y entonces ocupan páginas de prensa y de documentos judiciales: desordenan, riñen, roban, etc. Esta actividad que se desarrolla en los márgenes bárbaros de la ciudad civilizada moderna atrae por igual a trabajadores y patrones. Sin embargo, esta igualdad de fondo, en tanto se inscribe en los códigos del mantenimiento de la masculinidad de un sistema de sexo-género profundamente patriarcal, se diluye en la mantención de las formas en tanto está estratificada de acuerdo a los ingresos de ambos grupos. Así, se construyen circuitos paralelos de primera y segunda clase, en los que se puede acceder a sexo y alcohol de calidades diferenciadas. 
La capacidad de consumo adquirida por los asalariados les asegura su acceso a las chicas que fuman, ya que se paga con el fruto del trabajo, de modo que la dura tarea se ve premiada por la posibilidad de distraerse, además de resguardar y exhibir la preciada hombría, que constantemente se encuentra en juego e, incluso, cuestionada.

Pero la particularidad del servicio sexual está en quienes lo ofrecen y este factor es el que genera su carácter problemático y complejo: los cuerpos objeto, que no son otra cosa que las prostitutas. Mujeres, al fin y al cabo, tratadas como meros objetos de intercambio; en este sentido, profundamente modernizadas, llevando a su expresión más radical la noción de propiedad privada y libertad económica. En cualquier caso, si la sociedad del trabajo ha puesto en el mercado a las personas, esta consecuencia extrema sigue permaneciendo dentro del orden moderno del mundo, un orden que calificamos como económico sobre toda otra consideración, en el que incluso la noción de derechos está fuertemente inscrita en los circuitos de la producción.

De esta forma, se nos restituye un cuadro de modernidad compleja y atravesada por tensiones diversas pero, al fin, armonizadas: capital-trabajo, masculinidad-feminidad, civilización y marginalidad. A un alto precio, Osorno se celebra y proyecta hacia el futuro como la sociedad moderna que es y, como tal, lo hace invisibilizando su cara menos amable tras la pompa y brillo de los sones marciales y los discursos de un nuevo centenario.

\section{BIBLIOGRAFÍA}

Álvarez, Jaime (2003): "Bohemia, literatura e historia", en Cuadernos de historia contemporánea, No. 25, pp. 255-274.

Carreño, Luis (2006): "La irrupción del Estado en la Araucanía y las pampas, y la crisis de las curtiembres y las destilerías de alcohol de grano de Valdivia. 1850-1900", en Espacio Regional, Vol. II, No. 3, pp. 99-104.

Castel, Robert (1997): La metamorfosis de la cuestión social. Buenos Aires: Paidós.

Foucault, Michel (1992): Microfísica del poder. Madrid: La Piqueta.

(1998): Historia de la sexualidad, Tomo I. México D.F.: Siglo XXI.

Fraisse, Genevieve (1986): "El devenir del sujeto y la permanencia del objeto", en Cuadernos de Historia Universidad de Chile, No. 28, pp. 67-78.

Góngora, Álvaro (1994): La prostitución en Santiago, 1813-1931. Santiago de Chile: Universitaria.

Grothe, Raúl (2003): Historia y desarrollo de la región de "Los Lagos". Osorno: Austral. 
La Prensa (1921, 1941-1942, 1949, 1950-1960). Osorno.

Naredo, José Manuel (1996): La economía en evolución: historia y perspectivas de las categorías básicas del pensamiento económico. Madrid: Siglo XXI.

Offe, Claus (1992): La sociedad del trabajo, problemas estructurales y perspectivas de futuro. Madrid: Alianza.

Olavarría, José (ed.) (2001): Hombres: identidad/es y violencia. Santiago de Chile: FLACSO.

Olavarría, José y Valdés, Teresa (eds.) (1998): Masculinidades y equidad de género en América Latina. Santiago de Chile: FLACSO.

Oyarzo, Leonardo (2007): "Prostitución en Osorno a mediados del siglo XX". Tesis (Profesor en Educación Media con mención en Historia y Geografía). Osorno: Universidad de Los Lagos, Departamento de Ciencias Sociales.

Pateman, Carole (1995): El contrato sexual. Barcelona: Antrophos / UNAM.

PEDCH (2007): Fondo Archivos Judiciales: 1950-1951, Primera Comisaría de Osorno [DVD]. Osorno: Universidad de Los Lagos.

Peralta, Gabriel y Hipp, Roswitha (2004): Historia de Osorno. Osorno: Ilustre Municipalidad de Osorno.

Polanyi, Karl (1989): La gran transformación. Madrid: La Piqueta.

Rubin, Gayle (1986): "El tráfico de mujeres: notas sobre la 'economía política' del sexo", en Nueva Antropología, Vol. VIII, No. 30, pp. 95-142.

Servicio Nacional de Estadística y Censos (1952): XII Censo General de Población y I de Vivienda. Tomo VI: Regiones de Los Lagos y de Los Canales. Provincia de Osorno. Santiago de Chile: Servicio Nacional de Estadística y Censos, Departamento de Geografía y Censos.

Scott, Joan (2003): "Historia de las mujeres", en Burke, Peter (ed.): Formas de hacer historia, pp. 59-89. Madrid: Alianza.

Vásquez, Cristina (2009): "Antagonismos entre los discursos y los actuares de una sociedad conservadora, la violencia contra la mujer. Osorno 1949-1956". Tesis (Profesora en Educación Media con mención en Historia y Geografía). Osorno: Universidad de Los Lagos, Departamento de Ciencias Sociales. 
Vivar, José Luis (2007): "Borrachera: ¿forma de transgresión o simple alcoholismo? Mediados del siglo XX en la provincia de Osorno". Tesis (Profesor en Educación Media con mención en Historia y Geografía). Osorno: Universidad de Los Lagos, Departamento de Ciencias Sociales. 


\section{ANEXO}

\section{Plano 1 CIUDAD DE OSORNO EN 1960}

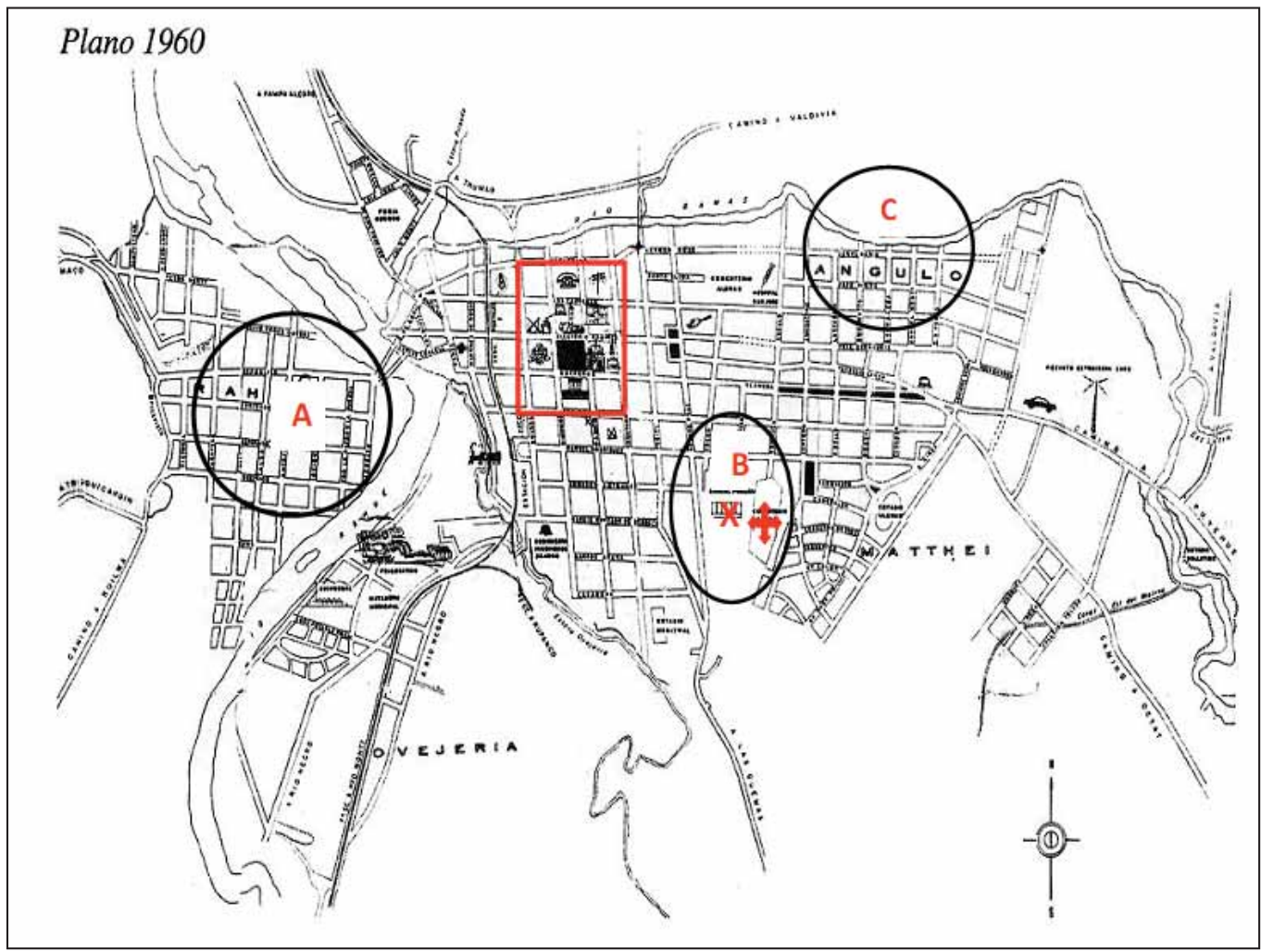

Fuente: elaboración propia en base a Peralta y Hipp (2004: 286).

\section{Simbología:}

A: RAHUE

B: $\quad$ PRAT

C: $\quad$ ANGULO

: CENTRO COMERCIAL E HISTÓRICO

X: CÁRCEL

$\stackrel{\checkmark}{\longrightarrow}$ : CEMENTERIO 